\title{
Fraud in Overseas Aid and the Challenge of Measurement
}

\section{Abstract}

Purpose The purpose of this paper is to explore the challenges of measuring fraud in overseas aid.

Design/Methodology/Approach The research is based upon 21 semi-structured interviews with key persons working in the delivery of aid in both the public and voluntary sectors. It uses the UK Department for International Development as a case study to applying more accurate measures of fraud.

Findings This paper shows there are significant challenges to using fraud loss measurement to gauge fraud in overseas aid. However, it argues along with other types of measures it could be used in areas of expenditure in overseas governments and charities to measure aid. Given the high risk of such aid to fraud it argues helping to develop capacity to reduce aid, of which measuring the size of the problem is an important part, this could be considered as aid in its own right.

Research Limitations/Implications The researchers were not able to visit high risk countries for fraud to examine in the local context views on the challenges of measuring fraud.

Practical Implications The paper offers insights on the challenges to accurately measuring fraud in an overseas context, which will be useful to policy-makers in this context.

Social Implications Given the importance of as much aid as possible reaching recipients it offers an important contribution to helping to reduce losses in this important area.

Originality/Value There has been very little consideration of how to measure fraud in the overseas aid context, with most effort aimed at corruption, which poses some of the same challenges, as well as some very different.

Keywords Overseas aid, Fraud, Measurement

Paper type Research paper

\section{Introduction}

In many countries around the world it is a time of austerity with swingeing cuts to public expenditure occurring. In some countries overseas aid has been shielded from the full-extent of austerity and the UK is one of these, where the aid budget has been set to increase substantially (from $f 8.1$ billion in 2011-12 to $f 10.6$ billion during 2014-15) (DFID, 2012). This expansion is occurring in many countries at high risk of fraud and corruption. As the House of Commons Public Accounts Committee (2011) in the UK noted: 
All of the countries in which the Department plans to increase its spending by more than $50 \%$ over the next four years have a score lower than 3.0 in the Transparency International index of the perceived extent of public sector corruption (on a scale which ranges from zero which represents 'highly corrupt' to 10.0 which represents 'very clean').

Overseas aid in developing and transition countries is generally at high risk of fraud and corruption (Transparency International 2006; and Fletcher and Hermann, 2012). Indeed the first major Public Expenditure Tracking Survey (PETS), (which identify both fraud, corruption and wastage) in the Uganda Education Department in 1996 found only 13\% of the annual capitation grant (student) reached the schools between 1991-95, with 87\% disappearing for private gain or spending on other unrelated purposes (Reinekka and Svensson, 2004). The increase in aid is also occurring against a backdrop of some political and media opposition to the increase (Martin and Groves, 2012).

It is therefore essential - particularly for supporters of overseas aid - that fraud and corruption is kept to a minimum. The first part of any strategy to deal with a problem should be to define the nature and size of it. However, much of the interest amongst donors has been upon measuring corruption (Kenny, 2009; Reinekka, and Svensson, 2004 and 2006; Seligson, 2006). Fraud and corruption overlap, but there are differences between the two problems, as will be illustrated later in this paper. Both face significant but different challenges in measuring (Samford et al., 2006; Levi and Burrows, 2008). Fraud has also spawned a variety of measures to gauge the size of the problem, beyond basic detected statistics (see, Levi and Burrows, 2008). Some of the tools will be explored later in this paper. 
However, one method which is gaining wider use for measuring fraud is the process of Fraud Loss Measurement (FLM) (Presidential Documents, 2010; Gee, Button and Bassett, 2011; Tunley, 2011; and Button et al, 2012). FLM has begun to become commonly used in the measurement of fraud in social security payments, health insurance, procurement payments, payroll, tax returns to name some (Gee et al 2011a and b). It is a process to measure fraud in a similar group of transactions based upon a sample, which are investigated to a higher standard than normal, to determine whether such transactions are correct, errors or fraudulent (Brooks et al. 2011). From this sample, levels of fraud, error and correctness are estimated according to a particular range and level of statistical confidence. It is based upon the principle that in a pyramid of transactions there will be a small number of detected frauds at the top, a large number of correct transactions at the bottom and a number of undetected frauds in-between, which can be detected when subjected to more rigorous scrutiny.

There are challenges to using FLM in general, which will be outlined below. However, overseas aid poses even more problems because of the way overseas aid is delivered by governments and other international organisations. This paper will largely use the Department for International Development (DFID) in the UK to illustrate the challenges of using FLM, although other countries and bodies will also be referred to where necessary. The paper will start by looking at the nature of fraud in overseas aid. To do this it is also necessary to deconstruct what is meant by fraud, corruption and related terms, as they are often used interchangeably whereas the authors argue they can be fundamentally different. The paper will then explore some of the different measures currently used by governments, multilateral bodies and Non-Governmental Organisations (NGOs) to measure fraud in overseas aid. The paper will then introduce FLM in greater depth as the most accurate means to measure fraud in many types of expenditure. Some of the challenges of using FLM in general will also be introduced. In presenting different types of measures where data is available, the scale of fraud in overseas aid will be presented. The paper will then move on to 
advocate a means for utilising FLM and related strategies in the difficult terrain of overseas aid to more accurately measure fraud.

The research for this paper was funded by DFID and to conduct the research they invited the researchers to East Kilbride, Scotland (where DFID is based) to interview various staff and secure appropriate documentation. Telephone and other video-link interviews were also conducted with various DFID, National Fraud Authority, Department for Work and Pensions and HM Revenue and Customs staff. In all 21 people were interviewed. Numerous documents have also been secured which were in the public domain, including a review of the way that international organisations and other government aid bodies themselves research the level of fraud in their areas

\section{Overseas Aid in Context}

The increase in overseas aid is occurring is occurring in countries at high risk of fraud and corruption against many organisations where the infra-structures to counter these risks are weak. As the House of Commons Public Accounts Committee (2011) was to comment on DFID in the UK:

The Department does not estimate levels of leakage through fraud and corruption, which undermines its ability to make informed investment decisions and gain assurance that it has appropriate and effective controls in place. Fraud investigation is reactive and reported levels of fraud are unbelievably low.

Further evidence of weaknesses emerged with the report by the Independent Commission for Aid Impact (2011: 1), which concluded:

Our assessment is that DFID's current organisation of responsibilities for fraud and corruption is fragmented and that this inhibits a coherent and strategic response to this critical issue. DFID needs to give significantly greater attention to the fight against corruption to manage this increasing risk. 
The report, overall, rated DFID amber/red which means, 'The programme meets some of the criteria for effectiveness and value for money but is not performing well. Significant improvements should be made.'

DFID faces the challenge of increasing aid rapidly, in environments which are high risk for fraud and corruption at a time when its administrative resources, in which the counter fraud capacity is located, will decline (The expanding budget of DFID is also going to occur alongside a real terms reduction of one third in the administration budget from $f 128$ million to $f 94$ million during the same period) (DFID, 2011a). This is a potentially toxic combination for accelerated rates of fraud and corruption which is unlikely to be detected by the UK government

It is therefore vital that the resources that are available are marshalled to counter fraud and corruption in the most effective way possible. Central to an effective counter fraud strategy is accurately measuring the scale and nature of the problem (CIPFA, 2006; Executive Office of the President, 2011; Gee et al, 2011a and b). Before the challenges in measuring the extent of fraud in overseas aid are considered it is important to distinguish between fraud and corruption.

\section{Fraud and corruption in overseas aid}

Many commentators and reports combine 'fraud and corruption' together and some talk of corruption, but also include fraud. A proper definition is not only important for a clear conceptual framework, but because the measurement of fraud and corruption pose very different challenges (see Samford et al, 2006). Corruption is also a very broad concept covering a wide range of behaviours. The Asian Development Bank (1998) defines corruption as, 'The abuse of public or private office for personal gain.' The essence of corruption is the abuse of a position by a person to secure some form of gain for themselves or another. There is much corruption - which although bad - may have little or no impact on the funds released. For example a corrupt public official may, for a 
kickback, drive down the cost of a contract by advising the favoured supplier of the lowest competitive bid. An official who takes bribes to employ a specific person may also not cause any actual financial loss to the funding stream. Similarly a politician might spend aid as it was supposed to, but that might be done in their own constituency, for their own tribe, political area etc. Technically (unless there are provisions for where it should be spent) this would not be fraud, but could be corruption.

However, corruption by an official could cause losses to aid funds and thereby be classified as fraud. For example, if a corrupt official built a palace using funds given to his/her government to build a hospital, that is an example of corruption and fraud. Wells argues fraud is, 'any crime which uses deception as its principal modus operandi'. England and Wales is unique in codifying the offence of fraud with the passage of the Fraud Act 2006 (Farrell et al 2007). This sets out a number of ways in which fraud can be committed, to which aid type frauds are added:

- Fraud by False Representation (this could cover the submission of false invoices for payment).

- Fraud by Failing to Disclose information (this could be a contractor is paid to treat 1000 children, but only treats 700 and does not disclose this to the funder).

- Fraud by Abuse of Position (this is where a person in a position of trust abuses their position such as an official diverting funds to their own personal account).

There are many examples of fraud by those in positions in trust, which could also be described as corruption. There are also lots of acts of fraud which are committed by those against governments, NGOs etc who are not in positions of trust or responsibility. A contractor who decides to inflate invoices or bills in full for unfulfilled contracted services is not committing corruption, but fraud. It is therefore better to consider fraud and corruption as two sets of partially overlapping criminal behaviours. 
This paper will focus upon the measurement of fraud. However, because Fraud covers some aspects of corruption, whenever reference is made to fraud in this paper it will also cover some aspects of corruption. Reference will also be made to corruption specifically when the broader range of deviance is considered. Measurement of corruption requires different methodologies and poses challenges beyond the scope of this paper (see Samford et al, 2006). There are a number of areas in the delivery of aid where fraud has occurred in the past. Some of the most common areas are listed below.

\section{Macro frauds}

- Fictitious or under-delivered projects: aid is given for a project which doesn't exist or what was expected to be delivered falls short but the same monies are still claimed.

- Double counting: a project is delivered but is paid for by multiple donors who do not know others are paying for it too.

- Diversion of funds: funds given for a specific area are diverted to others.

2. Micro frauds

- Ghost employees: employees who don't really exist are added to the payroll.

- Ghost suppliers: payments are made against invoices from companies which do not exist.

- False claims for pay: employees are paid for full contractual hours, but don't actually work them.

- False overtime/pay claims: employees over-charge for overtime not worked or submit false claims.

- False invoices: invoices are submitted by real suppliers for work not completed or for higher amounts.

- False expenses: exaggerated or false expenses submitted. 
- Diversion of aid: assets for projects such as food, supplies, equipment etc are diverted from legitimate uses for the gain of the fraudster.

- False competing bid information in contracting.

- Exploitation of petty cash payments.

- Purchase of overpriced goods and services.

- Purchase of unnecessary goods and services.

- Goods and services provided are falsified: truck part of aid and documents to prove delivered, but reality never was.

- Excessive purchase of goods and services: more fuel bought than required.

- Embezzlement: diversion of funds to fraudster's account.

The list is not exhaustive. They range between macro-level frauds, which require leadership level deviance, such as a government official fabricating a fake project, to the micro-level where more typically frauds are directed against projects or bodies receiving aid, such as fictitious contractor invoices or inflated employee expense claims (for a more detailed consideration see Appleton, 2011; Fletcher and Herrmann, 2012). The extent of fraud in overseas aid will be examined in the next section as some of the different measures which are used to gauge the level of fraud are outlined.

\section{Measuring Fraud in Overseas Aid}

Fraud presents significant challenges to measurement. There are a wide range of different methodologies used to measure fraud in organisations (Levi and Burrows, 2008). Most governments, multilateral bodies and NGOs prefer not to publicise statistics of levels of fraud and those which are in the public domain, tend to be detected.

\section{Detected}


The most common measure of fraud in organisations is detected levels of fraud usually by number of cases and by value. By its very nature fraud is a hidden crime with payments disguised as legitimate expenditure, there is not always a 'body' to determine a crime has taken place, as frauds are often hidden as legitimate payments. Frauds can and do often go on for a long time undiscovered (ACFE, 2012). Detected frauds thus represent the tip of the iceberg (Shapiro, 1985). Levels of detected fraud also rely on the effectiveness of counter fraud structures. Perversely better protected organisations tend to have higher detected rates than poorly protected as they tend to do more to find fraud. A low level of detected fraud is therefore not a sign of a low level of fraud. Most published data on levels of fraud in overseas aid are just the detected cases and losses.

In Australia, for example, AusAID publishes detected fraud losses. Its approach to fraud is laid out in its Fraud Policy Statement and figures are given in its annual Fraud Fact Sheet (AusAID, 2011). During 2010-11, 125 cases of alleged, suspected or detected fraud were reported to AusAID. In addition a further 24 potential instances were reported during the year but were found not to have involved fraud or not to have involved AusAID. AusAID estimates that the amount involved in the 1252010 11 cases is AUS $\$ 1.6 \mathrm{~m}$. Of this amount, AUD $\$ 400,000$ had been recovered or prevented from being lost and the potential net loss to AusAID was therefore estimated to be approximately AUD $\$ 1.26 \mathrm{~m}$.

\section{Public Expenditure Tracking Survey (PETS)}

PETS are used to assess the wastage, fraud and corruption in expenditure. As such, although they do measure fraud alone, they capture other leakages too. They look at what happens to the original money which was allocated for a project as it travels through different layers of bureaucracy to ultimate delivery. As Reinekka and Svensson (2006: 360) argue: 
It is therefore useful as a method for locating and quantifying political and bureaucratic capture, leakage of funds, and problems in the deployment of human and in-kind resources, such as staff, textbooks, and drugs.

The first major PETS was on the Ugandan Education department in 1996. The motivation was that despite substantial increases in expenditure there had not been similar increases in primary school enrolment. The PETS found that only $13 \%$ of the annual capitation grant (student) reached the schools between 1991-95, with $87 \%$ disappearing for private gain or spending on other unrelated purposes (Reinekka and Svensson, 2004). This led to PETS been implemented in a number of other countries, which also showed generally substantial leakage.

A variation of the PETS is the Frontline Provider Survey or Quantitative Service Delivery Survey (QSDS). This assesses front-line services against the expectations from the funding provided. Similar to FLM a statistically valid sample of locations is identified and then visited on an unannounced basis to assess service delivery. A QSDS in Bangladesh found 35\% and $40 \%$ of health-workers and doctors absent (Reinekka and Svensson, 2004 and 2006). This shows that even when funding reaches the service point, other factors can further add to the attrition to the original funds.

PETS uncover the attrition in funds which includes fraud, corruption, error as well as bureaucracy and inefficiency. They are, however, very resource intensive to undertake and uncover a wider range of leakages than fraud and error. Indeed PETS are estimated to cost at least $\$ 50 \mathrm{k}$ to $\$ 100 \mathrm{k}$ per project (Koziol and Tolmie , 2010; Reinekka and Smith, 2004) .

\section{Fraud Loss Measurement}

FLM is a mechanism to measure fraud which is growing in many organisations. This article will argue later FLM offers a means to gauge the extent of fraud, particularly micro frauds, in overseas aid. 
Before these arguments are considered, however, it would be useful to outline in more depth the nature and challenges of using FLM for overseas aid.

FLM is an assessment of a statistically valid sample of transactions within a given population to determine whether they are fraudulent, an error or correct (clear standards are set to define fraud and error and this usually involves the civil definition of fraud). It is important to note the thorough investigations which take place on the sample transactions or, as the White House (cited in Hatch and McMurty, 2011: 19) notes:

investigations in which specialized private sector auditors use cutting-edge technology and tools to scrutinize government payments and then find and reclaim taxpayer funds made in error or gained through fraud (emphasis added).

These investigations go beyond a normal assessment and there is also an expectation to recover losses from the payments made in fraud and error (in the USA this is known as Payment Recapture Audits or Recovery Audits). They are therefore more than an academic exercise to gauge the size of the problem. From this assessment it is then possible to accurately estimate to a given statistical level of confidence and tolerance range the true extent of fraud and error. This is usually presented as a Fraud Frequency Rate (FFR), which is the number of transactions which are fraudulent or errors and the Fraud Loss Rate (FLR), which is monetary value of losses (Brooks et al, 2011; Gee, Button and Bassett, 2011). In the USA fraud and error are combined under 'improper payments'. FLM has largely been used in large public sector organisations relating to social security payments, taxation, contractor payments and for procurement and insurance frauds in the private sector. Indeed in the USA some Federal bodies are required to undertake such measurement under the Improper Payments Information Act 2002 and the Improper Payment Elimination and Recovery Act 2012 (Hatch and McMurty, 2010; Tunley, 2011). Of those FLM exercises in the public domain, or which 
came to the attention of Gee et al (2011b) 203 exercises have been identified producing an average fraud and error loss of $5.67 \%$.

FLM is one of the more accurate methods to measure fraud. There are, however, some issues which need to be considered. First of all large sample sizes are needed for the more accurate outputs. Traditionally FLM exercises have been designed on the following basis:

Margin of error $(\mathrm{T})+/-1 \%$ or $+/-2.5 \%$

Confidence levels (CL) of $95 \%$ or $90 \%$

These parameters produce the following sample sizes assuming the FLR is $4 \%$.

$\mathrm{T}=+/-1 \%$ with $\mathrm{CL}=95 \%$ at $\mathrm{P}_{\mathrm{p}}=4 \%$ produces a sample size of $\mathrm{n}=1,475$

$\mathrm{T}=+/-2.5 \%$ with $\mathrm{CL}=95 \%$ at $\mathrm{P}_{\mathrm{p}}=4 \%$ produces a sample size of $\mathrm{n}=236$

$T=+/-1 \%$ with $C L=90 \%$ at $P_{p}=4 \%$ produces a sample size of $n=1,039$

$\mathrm{T}=+/-2.5 \%$ with $\mathrm{CL}=90 \%$ at $\mathrm{P}_{\mathrm{p}}=4 \%$ produces a sample size of $\mathrm{n}=166$

For many organisations high levels of accuracy are desired and this means 1000 plus samples. As these involve detailed investigation, it is a labour intensive process, particularly if all information required to make an assessment is not readily available. This means it can be an expensive exercise costing anything from $f 30 \mathrm{k}$ to $f 100 \mathrm{k}$ per FLM, depending upon the sample size and the ease of conducting it. For many organisations - particularly those who perceive (perhaps rightly so) that they have low levels of fraud, paying a large sum of money to be told that the fraud level is very low is not appealing. Linked to the cost is the potential disruptive impact on the subject organisations, including on the morale of the ethical majority of employees, especially as each sample transaction is investigated as if it were a fraud. The third issue relates to automation and efficiency: to make the process less disruptive it is suited to organisations where records are kept in a coherent way, usually online. FLM involving paper trails are not impossible, but add to the cost. The fourth issue is that it is 
suited to large numbers of similar transactions within a specified population, such as payroll, procurement, social security payments or insurance claims. Thus it is not suited to assessing the total fraud in a department, organisation, sector etc, unless they are broken down to smaller chunks of similar transactions before later aggregation. Another challenge is when fraud and error are combined in a single 'improper payments' category and not distinguished. Although they are both a loss to the organisation the solutions for them are very different. Considering the nature of the task, overall FLM is more suited to larger organisations with higher transactional volumes and values.

In the UK FLM exercises are undertaken regularly by the Department for Work and Pensions (DWP) (responsible for paying social security), HM Revenue and Customs (responsible for collecting taxes), and the National Health Service (NHS) (the public provider of healthcare in the UK). The DWP invests a great deal of time in measuring fraud losses and more generally in investigation and prevention (DWP, 2011 and Shawyer and Walsh, 2007). It conducts FLM exercises regularly across a range of benefits it issues, which enables it to estimate a global figure of fraud losses, which is largely the result of FLM, although the currency for some types of expenditure does vary. It is also important to note the DWP invests about $f 10 \mathrm{M}$ per year on fraud measurement. This is split between $f 0.4 \mathrm{M}$ on

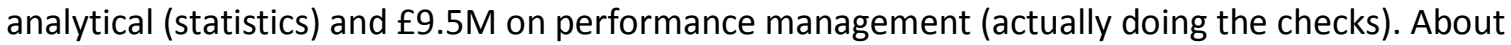

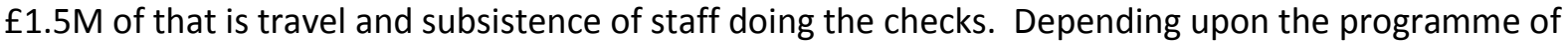
measurement there could be between 200 to 300 staff engaged in measurement activity. Fraud and error rates vary by benefit from $0.1 \%$ for pensions to $6.5 \%$ for jobseekers allowance. The DWP also distinguish between fraud and error rates with the fraud alone rate varying from $0.0 \%$ for pensions to $4.1 \%$ for jobseekers allowance. It is also important to note the FLM exercises are not conducted every year for every benefit (DWP, 2011). HMRC also invests significantly in accurate measurement mechanisms to determine the 'tax gap' using FLM techniques (HMRC, 2011). The NHS has also made use of FLM in the past for a number of areas of expenditure. These have included: patient prescription payments, patient optical fraud, procurement, and dental and optical contractor fraud 
to name most. In its most recent performance statistics it has highlighted a FLM exercise related to medical locum agency invoicing with a fraud loss rate of $4.7 \%$ (NHS Protect, 2011).

FLM is a very accurate means to measure fraud. It is, however, costly depending upon the level of statistical accuracy and the complexity of undertaking the exercise. It is also largely untried in overseas aid. This paper will now turn to the challenges of applying FLM by using a case study of DFID in the UK.

\section{Is Fraud Loss Measurement Suitable for Overseas Aid?}

This paper will now move on to explore some of the challenges in using FLM as a means to measure fraud in overseas aid. It will illustrate the different modalities of aid and the different challenges these pose. It will also explore issues such as the systems and place and securing consent to actually carry out the FLM. In doing so it will draw upon the example of DfID.

\section{Different modalities of aid}

The first significant hurdle is the complexity of the different modalities of aid provided by DFID (which is common for most governments) (Fritz and Kolstad, 2008; and Fletcher and Herrmann, 2012). What is unique compared to other government departments is the substantial amount of funds which is effectively handed over to other bodies to spend. Other governments, multilateral bodies and NGOs all receive substantial funds to spend, often with only very broad purposes agreed. There is not a specific contract like a large company would have for the purchase of a fleet of cars or a government department would have in funding school improvements in the UK. Rather in much of the overseas aid budget the onus is on the receiving body to be in control and ensure the money is used legitimately. The funding transfers go from DFID to the multilateral body then go through to projects. In the multilateral body the funding may go for membership contributions, research, administration costs as well as to fund further projects. The projects may be delivered direct by the 
multilateral body or it may fund other bodies such as governments, NGOs (sometimes referred to as Civil Society Organisations - CSOs) to undertake work. To complicate matters further some of the projects may be funded by more than one body. The stream of UK funding is therefore lost in the complexity of other multiple funders and the variety of streams that it contributes to. Indeed almost two thirds of DFID funds are delivered through multilateral bodies. Thus there is already a minority of the budget where DFID has control, and as we shall see shortly, this control diminishes further when these funding streams are explored.

To use the analogy of the DWP in the UK (as they are often used as a model of fraud measurement), it would be like the DWP deciding to outsource welfare payments to a dozen or so charities leaving them with much of the discretion to set payments and eligibility etc and where some of those charities then further sub-contract and then the DWP seeking to gauge fraud amongst them. Unlike the current arrangements where the DWP have common systems in place to undertake FLM it would be faced with different systems used by charities, different comparators, multiple deliverers, different welfare regimes and the challenge of getting the charities to co-operate. It would not be impossible to conduct a FLM exercise but would be a much more difficult, complex and expensive task.

The picture is not any simpler when bilateral aid is considered. Some funds are given to governments direct either through general budget support or sector budget support. As an example in the 201011 budget this accounted for almost $10 \%$ of the DFID budget. Essentially a pot of money is given to the government department to spend, usually for a general purpose, such as 'poverty reduction', or 'improving health'. Often this support is provided alongside other donors, both bilateral and multilateral. This may involve expenditure on multiple projects. To therefore trace fraud in funds provided by a bilateral aid agency in such a pipeline would also be incredibly difficult. The government may also be unwilling to facilitate FLM and the systems in place may also make this difficult. 
Regarding debt relief, this is provided to countries according to the IMF 'Debt Relief Under the Heavily Indebted Poor Countries (HIPC) Initiative.' This involves a complicated assessment of a country according to objective criteria. The actual amount of debt relief is unlikely to be at risk of fraud, that is, a country manipulating data to secure debt relief. However, the debt relief is granted on the expectation that that money is then spent on 'poverty reduction'. Should the government spend the money on arms or luxury palaces, that would be fraudulent expenditure. Therefore there would be scope to measure fraud in this area by assessing government expenditure and assessing whether it has been spent on what would be expected.

Another significant slice of money is given to NGOs. Given there is no contractual mechanism to force them to conduct a FLM exercise at present they may also decline to participate. Their systems in some countries may also make it difficult to conduct FLM. They are also involved in humanitarian assistance, which also poses challenges, as will now be illustrated.

Discussions with some DFID staff as well as other evidence suggested humanitarian assistance is a high risk for fraud, theft and corruption (Willetts-King and Harvey, 2005; Ewins et al 2006; Transparency International, 2006; Abraham, 2007). This is because there is an overriding desire to get aid to the recipients as quickly as possible to save lives. The assessment procedure a bilateral aid agency may use is therefore a much quicker process. Another issue is that if aid, such as blankets, ends up for sale on a market, it is fraud if they were sold by officials, but if the recipients have sold them on, is that fraud? In reality no, but how would one determine this? Some humanitarian aid is food and water and clearly several months later determining whether it all reached those who needed it would be very difficult to determine. Finally much humanitarian aid is delivered by NGOs, multilateral bodies and governments, so the same issues related to multilateral and bilateral aid above apply. Investigating the fraud losses in aid already delivered in a location which is likely to be fragile would therefore pose challenges. By the nature of the aid the importance of time and response and the absence of interference in delivery are very important. Indeed there has been 
recent coverage that the slow response to the 2010-2011 crisis in East Africa led to deaths of between 50,000 and 100,000 (BBC News, 2011). Conducting FLM might interfere with the response or at the very least distract attention from the effort. There are therefore significant hurdles to conducting FLM in humanitarian aid.

There is also the more general challenge of fragile states, such as Afghanistan and Somalia. First of all these states are very dangerous with significant security risks. Secondly, they are often chaotic and do not have appropriate systems in place or these are not used as they should be. Significant challenges therefore also exist for conducting FLM in these areas (Willetts-King and Harvey, 2005; and Ewins et al 2006).

\section{Appropriate systems and consent}

Another issue to consider with FLM is the practicalities of conducting FLM in some countries and organisations where systems may not make this easy (Ewins et al 2006). At the other extreme the authors have seen how an FLM can be applied to fraud insurance claims. The company has all the data from forms, letters, recorded interviews with the claimant etc on one entry in a substantial database. If such a claim is selected in a sample for investigation, all information would be there for the investigator to assess from a laptop. In an aid context a government or NGO may have much more chaotic systems and often limited IT. These barriers would not rule out FLM, but would increase the costs. There would also be a case for using the process to also enhance systems.

The final challenge to conducting FLM is simply securing consent. At the moment much of the aid programme does not require FLM to be undertaken. Until this is mandated as part of aid it would require the co-operation of multilateral bodies, overseas governments and NGOs. They might say no or say yes but either wilfully or simply by the nature of the way they operate not provide the necessary support for the FLM to take place effectively.

\section{FLM as Aid?}


Leakages for fraud amount to a significant sum of money. Reducing it and therefore increasing the amount of aid that reaches its destination, could therefore be considered as a form of aid in its own right. There is also the additional benefit of creating capacity and approaches to countering fraud that spread beyond the areas of aid expenditure. Countering fraud effectively in countries and NGOs therefore has a wider benefit. Therefore the methodology for FLM should not be seen as an additional layer of bureaucracy but as a programme in its own right to develop capacity in measurement and countering fraud which has a wider benefit on the government and society of aid recipients. As was noted earlier the measurement of fraud is the foundation of any counter fraud strategy.

\section{A Basket of Measures}

FLM should be used alongside other measures to gauge the size of the problems of corruption, wastage, inefficiency etc. It should be targeted at areas where it is most suited in areas where there are common transactions. Governments receiving general and sector budget support could be asked as a condition of aid to conduct FLM on areas of expenditure high risk to fraud. For example, DFID has been funding annually a $£ 100$ million+ health programme in Kenya and this could be subjected to FLM on specific aspects of expenditure. These could include: the procurement, payroll etc in the Kenyan Ministry of Health. Indeed for payroll alone there have already been many studies showing substantial numbers of 'ghosts' on payroll in developing countries. For example in Honduras $5 \%$ of teachers and $8.3 \%$ of workers; Uganda $20 \%$ of teachers (Reinekka, and Svensson, 2004).

Multilateral bodies and NGOs could also be encouraged and in some cases mandated to conduct FLM on aspects of their expenditure, thus stimulating strategies to deal with it. Once an official or politician or manager has hard numbers of fraud losses it is very difficult not to do something. In essence, therefore, the measurement of fraud is moved to those who actually spend the aid. Over time a dataset of measured fraud losses would emerge by multilateral body, country, department, NGO etc. With other assessments (such as of the effectiveness of counter fraud strategy), the 
national and organisational cultures etc it may be possible to undertake multivariate analysis to identify the most effective strategies and the level of risk of fraud (see Holtfreter, 2004; and 2008 for early work offering foundations in this area).

It would also be important for donor organisations to also conduct an FLM on certain aspects of expenditure. It would send out a clear message to the agency staff and its partners that it was serious about fraud. If FLM exercises are going to be mandated and encouraged in other organisations, it needs to set the example by conducting one on itself. The first question many multilateral bodies, NGOs and governments asked to conduct FLM will be: "Do you do it?"

FLM is well suited to the mirco-frauds in types of expenditure encompassing similar transactions. There are other measures such as PETS and QSDS which also have a role to play in securing the full picture of fraud and corruption in overseas aid. Using a combination of measures provides a basis to accurately identify the nature and scale of the problem, so the most effective action can be taken. Publicising the true cost of these problems, which is likely to be high, also focuses the minds of politicians and officials to do something about it.

\section{Conclusion}

This article has set out some of the main measures used and which could be used to gauge the extent of fraud in overseas aid. It has focussed upon FLM which is emerging as a common means to measure fraud, introducing some of the key principles of it, where it is used and some of the general limitations. Using a case study of DFID in the UK the paper then investigated whether FLM could be used to gauge the size of the fraud problem. This is a very contentious area given increases in expenditure at a time of retrenchment in almost every other government department. The paper identified a number of significant challenges to using FLM. Some of the most salient included the nature of expenditure, with the majority been spent by other bodies further down the aid pipeline 
by multilateral bodies, governments and NGOs; the humanitarian aid context, the nature of fragile states and the profile of transactions. Despite the challenges the paper argued FLM is a central aspect of a counter fraud strategy and it should be undertaken where the aid money is actually spent: DFID itself, multilateral bodies, overseas governments and NGOs in specific areas of expenditure suited to FLM. A programme of FLM alongside other measurement tools would produce extensive data on the size and nature of the problem, which could then provide the basis for a more effective strategy to deal with it. Undertaking such an approach should then lead to reduced levels of fraud and ultimately more aid reaching those who need it.

\section{Acknowledgements}




\section{References}

Abraham, A. (2007) 'Tsunami Swamps Aid Agency Accountability: Government Waives Requirements', Australian Accounting Review, 17(1), pp. 4-12.

ACFE. (2012) Report to the Nations on Occupational Fraud and Abuse 2012 Global Study. Austin: ACFE.

Appleton, R. (2011) Indentifying, Addressing and Preventing Fraud and Financial Misappropriation. Powerpoint Presentation, available online at http://www.theglobalfund.org/en/ . Last accessed 29 November, 2012.

Asian Development Bank (1998) Anticorruption Policy, available online at http://www.adb.org/documents/anticorruption-policy. Last accessed at 5 December, 2011.

AUSAID (2011) Fraud control at AusAID, available online at http://www.ausaid.gov.au/publications/pubout.cfm?ID=7618 68767414705 9251\&Type= Last accessed at 5 December, 2011.

BBC NEWS. (2011) Slow Response to East Africa Famine 'Cost Lives', available at http://www.bbc.co.uk/news/world-africa-16606021. Last accessed at 5 December, 2011.

Brooks, G., Button, M. And Gee, J. (2012) 'The Scale of Healthcare Fraud: A Global Evaluation', Security Journal, 25(2), pp .76-87.

Button, M., Gee, J. And Brooks, G. (2012) 'Measuring the Cost of Fraud: An Opportunity for the New Competitive Advantage', Journal of Financial Crime, 19(2), pp. 65-75.

CIPFA (2006), Managing the Risk of Fraud Actions to Counter Fraud and Corruption Red Book 2 (London: CIPFA) .

DWP (2011) Fraud and Error in the Benefit System: Preliminary 2010/11 Estimates, available at http://statistics.dwp.gov.uk/asd/asd2/fem/fem oct09 sep10.pdf, p 12. Last accessed at 14 November, 2011.

DFID (2012) Business Plan 2012-2015, available http://www.dfid.gov.uk/Documents/DFIDbusinessplan2012.pdf . Last accessed 12 December 2012.

DFID (2011a) Business Plan 2011-2015, available at http://www.dfid.gov.uk/Documents/DFIDbusiness-plan.pdf. Last accessed 20 January, 2012. 
DFID (2011b) DFID Expenditure on Development 2006/07-2010/11', available at www.dfid.gov.uk/Documents/publications1/.../Table\%203 P1.xls . Last accessed 20 January, 2012.

DFID (2011c) Monthly spend over f500, available at http://www.dfid.gov.uk/About-us/How-wemeasure-progress/DFID-spend/Last accessed 9 November, 2011.

DFID. (2011d) List of DFID projects, available at http://projects.dfid.gov.uk/ Last accessed 9 November, 2011.

DFID (n.d.) Unclassified document 20110930 Draft CAS Fraud Error Debt Definition v0 4 p9 supplied by DFID.

Ewins, P., Harvey, P., Savage, K. And Jacobs, A. (2006) Mapping the Risk of Corruption in Humanitarian Action, available at http://www.odi.org.uk/resources/docs/874.pdf Last accessed 9 November, 2011.

Executive Office Of The President (2011) Appendix C. Requirements for the Effective Measurement and Remediation of Improper Payments, available at

http://www.whitehouse.gov/sites/default/files/omb/memoranda/2011/m11-16.pdf Last accessed 20 January, 2012.

Farrell, S. Yeo, N, Ladenburg, G. (2007) Blackstone's Guide to the Fraud Act 2006. Oxford: Oxford University Press.

Fletcher, C. And Herrmann, D. (2012) The Internationalisation of Corruption (Farnham: Gower).

Fritz, V. And Kolstad, I. (2008) Corruption and Aid Modalities. Anti-Corruption Resource Centre, available at http://www.cmi.no/publications/file/3102-corruption-and-aid-modalities.pdf. Last accessed 20 January, 2012.

Gee, J., Button, M. And Bassett, P. (2011) Fraud Loss Measurement - A Short Guide to the Methodology and Approach. London: PKF/CCFS.

Gee, J., Button, M. And Brooks, G. (2011a) The Financial Cost of Healthcare Fraud. What the Data from Around the World Shows. London: PKF/CCFS.

Gee, J., Button, M. And Brooks, G. (2011b) The Financial Cost of Fraud. What the Data from Around the World Shows . London: PKF/CCFS.

Global Fund (2011) Results with Integrity: The Global Funds response to Fraud, available at www.theglobalfund.org/.../Core_ResultsWithIntegrityResponseToFraud_WhitePaper_en. Last accessed 20 January, 2012. 
Hatch, G. And Mcmurty, V., A. (2010) Improper Payments Act of 2002: Background, Information and Assessment, Congressional Research Service, available at

http://www.policyarchive.org/handle/10207/bitstreams/18930.pdf. Last accessed 20 January, 2012.

Holtfreter, K. (2004) 'Fraud in US Organisations: An Examination of Control Mechanisms', Journal of Financial Crime, 12(2), pp. 88-95.

Holtfreter, K. (2008) 'Determinants of Fraud Losses in Nonprofit Organisations', Nonprofit Management and Leadership, 19 (1), pp. 45-63.

Independent Commission On Aid Impact (ICAI) (2011) The Department for International Development's Approach to anti-Corruption, available at http://icai.independent.gov.uk/wpcontent/uploads/2010/11/DFIDs-Approach-to-Anti-Corruption.pdf. Last accessed 20 January, 2012.

Kenny, C. (2009) 'Measuring Corruption in Infrastructure: evidence from Transition and Developing Countries', Journal of Development Studies, 45 (3), pp 314-332.

Koziol, M. And Tolmie, C. (2010) Using Public Expenditure Tracking Surveys to Monitor Projects and Small-scale Programs - A Guide. Washington DC: The World Bank.

Levi, M. And Burrows, J. (2008) 'Measuring the Impact of Fraud in the UK: A Conceptual and Empirical Journey', British Journal of Criminology, 48(3), pp. 293-318.

Levi, M., Burrows, J., Fleming, H. And Hopkins, M. (2007) The Nature, Extent and Economic Impact of Fraud in the UK. London: ACPO.

Martin, D. and Groves, J. (2012) Tory grassroots 'despair' at $£ 12 b n$ foreign aid spree: I haven't met one backbencher who agrees with Cameron, says ex-minister. Daily Mail Online, available at http://www.dailymail.co.uk/news/article-2209178/Tory-grassrootsdespair-12bn-foreign-aid-spree-I-havent-met-backbencher-agrees-Cameron-says-exminister.html\#ixzz2F2gcUtHr . Last accessed 13 December 2012.

National Fraud Authority (NFA) (2012) Annual Fraud Indicator. London: NFA.

NHS Protect (2011) NHS CFS Performance Report 10/11, available at http://www.nhsbsa.nhs.uk/Documents/CounterFraud/PERFORMANCE REPORT.pdf. Last accessed 20 June, 2012.

Presidential Documents (2010) Memorandum of March 10, 2010 Finding and Recapturing Improper Payments, available at http://www.whitehouse.gov/sites/default/files/omb/assets/financial improper/03102010 imprope r payments.pdf. Last accessed 20 June, 2012.

Public Accounts Committee (2011) DFID Financial Management, available at http://www.publications.parliament.uk/pa/cm201012/cmselect/cmpubacc/1398/139804.htm. Last accessed 20 June, 2012. 
Reinekka, R. And Smith, N. (2004) Public Expenditure Tracking Surveys in Education, available at http://www.unesco.org/iiep/PDF/pubs/Reinikka.pdf. Last accessed 20 June, 2012.

Reinekka, R. And Svensson, J. (2006) 'Using Micro Surveys to Measure and Explain Corruption', World Development, 34 (2), pp. 359-370.

Samford, C., Shacklock, A., Connors, C. And Galtung, F. (eds) (2006), Measuring Corruption. Aldershot: Ashgate.

Seligson, M. (2006) 'The Measurement and Impact of Corruption Victimisation: Survey Evidence from Latin America', World Development, 34 (2), pp. 381-404.

Shawyer, A., and Walsh, D. (2007). Fraud and Peace: Investigative Interviewing and Fraud Investigation. Crime Prevention and Community Safety: An International Journal 9(2), 102-117.

Transparency International (2006) Corruption in Humanitarian Aid, available at http://www.transparency.ca/Reports/Readings/SR-P-working paper humanitarian aid.pdf. Last accessed 20 June, 2012.

Tunley, M. (2011) 'Uncovering the Iceberg: Mandating the Measurement of Fraud in the UK', International Journal of Law, Crime and Justice, 39(3), pp. 190-203.

Wells, J., T. (1997). Occupational Fraud and Abuse. Dexter, Michigan: Obsidian.

Willitts-King, B. And Harvey, P. (2005) Managing the Risk of Corruption in Humanitarian Relief Operations, available at http://www.odi.org.uk/resources/docs/1977.pdf . Last accessed 20 June, 2012. 